\title{
Study on the Training System for the Mechanical Engineering Students Oriented to Occupational Health
}

\author{
Ping Zhang ${ }^{1}$, Fengyi Liu ${ }^{2}$, Pengbo Zhang ${ }^{3}$, Yan $\mathrm{Fu}^{4}$ and Jie Tian ${ }^{5, *}$ \\ 1,2,3,4 College of Architecture and Art, Hefei University of Technology, Hefei, Anhui, 230601, China \\ ${ }^{5}$ College of Mechanical Engneering, Hefei University of Technology, Hefei, Anhui, 230601, China \\ *tianjie@hfut.edu.cn
}

\begin{abstract}
Industrialization has brought great changes to the world, but along with the depth of the process, it has also brought unprecedented harm to people's health and safety. Occupational health has become a common concern in the world today. Therefore, it is necessary to strengthen the occupational health and safety education, so that practitioners have a special ability to distinguish and prevent occupational hazards of knowledge and skills. The problems of health and safety are not only about technical issues, but also about the level of conception. This project has broken the traditional mode of teaching thinking, while introducing the concept of health into the occupation education, and implementing the whole teaching system and related courses, finally, building the idea of engineering education by taking health as the core. In this paper, authors tried to establish the systematic, scientific, harmonious engineering occupation health teaching system, to achieve training objectives. This teaching system can improve the realization of occupational health and safety education of people, and solve related contents and other substantive issues systematically. From the essential factors of engineering career, students not only master the engineering knowledge, but also have a sense of humanistic care, which can help people to work well and healthily.
\end{abstract}

Keywords: Occupational Health, Engineering career, Training system

\section{Introduction}

With the rapid development of the industrialization process, three big problems have appeared. Such as the excessive practitioners, occupational health and safety risks. The problems of health and safety are not only about technical issues, but also about the level of conception. At present, the domestic engineering education has begun to pay attention to improve the realization of occupational health and safety education of people, but the discussion is still in the initial stage, even limited to a report, a course, rather than the teaching system. Nobody care how to solve related contents and other substantive issues systematically. Therefore, students of engineering need to understand the relevant occupational hazards, and carry out the concept as follows into the training system, "everyone should have occupational health and safety awareness and knowledge and skills."

In the course of the study, the authors searched a lot of literature, then found that there are some articles about environmental, safety, and health engineering, some articles about occupational hazards and health care, but there is little about occupational health and safety education. In view of the situation, the research in this article is a useful supplement.

\section{Recognizing Occupational Health in the Knowledge System of Mechanical Engineering}

\subsection{Awareness of occupational health}

Occupational health is to study and prevent the health problems caused by career for people at work. Many of these hazards have cumulative effects, and they can be exposed in a period of time. Because these effects are not direct and not obvious, it is necessary to make people vigilant, then to reduce or avoid occupational diseases.

In broad terms, health hazards can be divided into four categories: physical, chemical, biological and ergonomic. Occupational hazards are mainly divided into four categories: physical, chemical, biological and physiological and psychological. According to their sources, it can be summarized as three categories: occupational hazards associated with the production process; occupational hazards related to the labor process; occupational hazards related to the working environment.( Fig.2.1) 
In the occupational population, the diseases caused by the above factors are called occupational diseases, they were caused by professional factors and were the important factors in the absence of workers, meanwhile, they are main matters in occupational health.

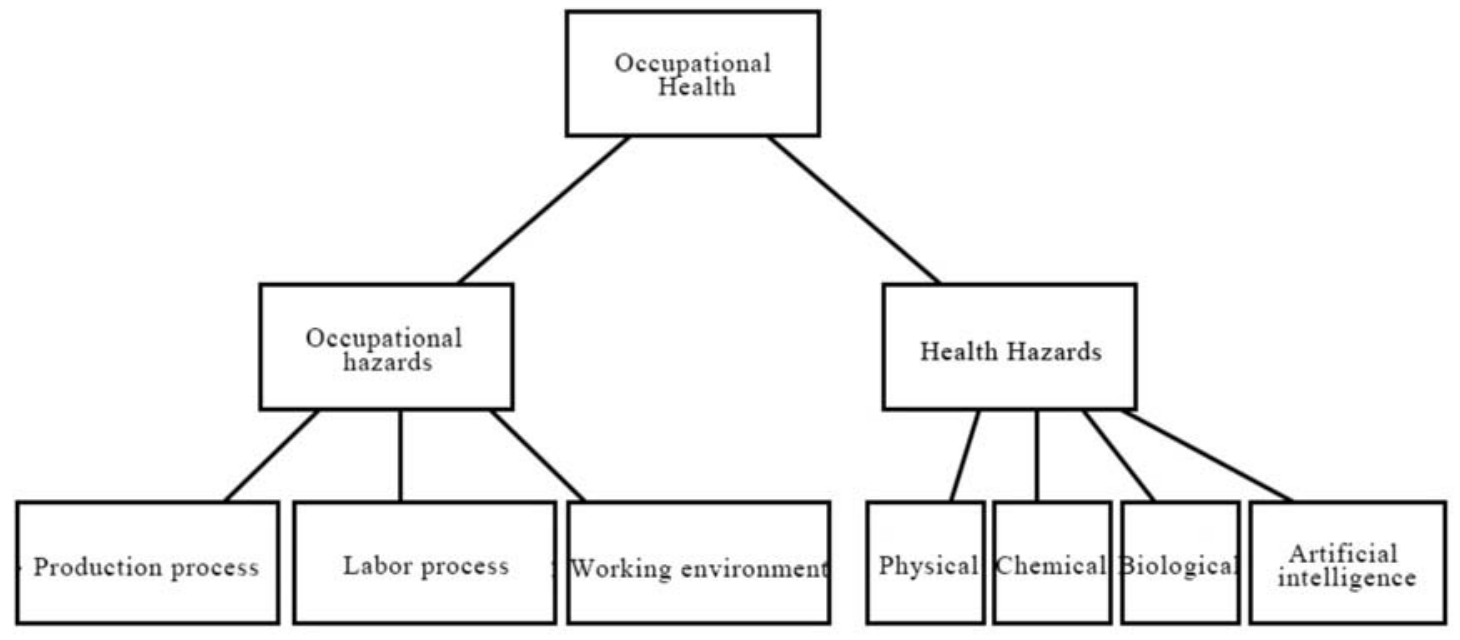

Fig.2.1 Classifications of occupational health

\subsection{The relationship between mechanical engineering knowledge system and the skills of} occupational health and safety knowledge

Mechanical engineering includes the knowledge of mechanics, power electronics, computer application technology, information processing technology and modern design methods. Traditional engineering education focus on technology, and train people to solve the engineering problems of design and manufacture, but human often fall into neglect. The needs of workers were totally be neglected, so health hazards are emerging.

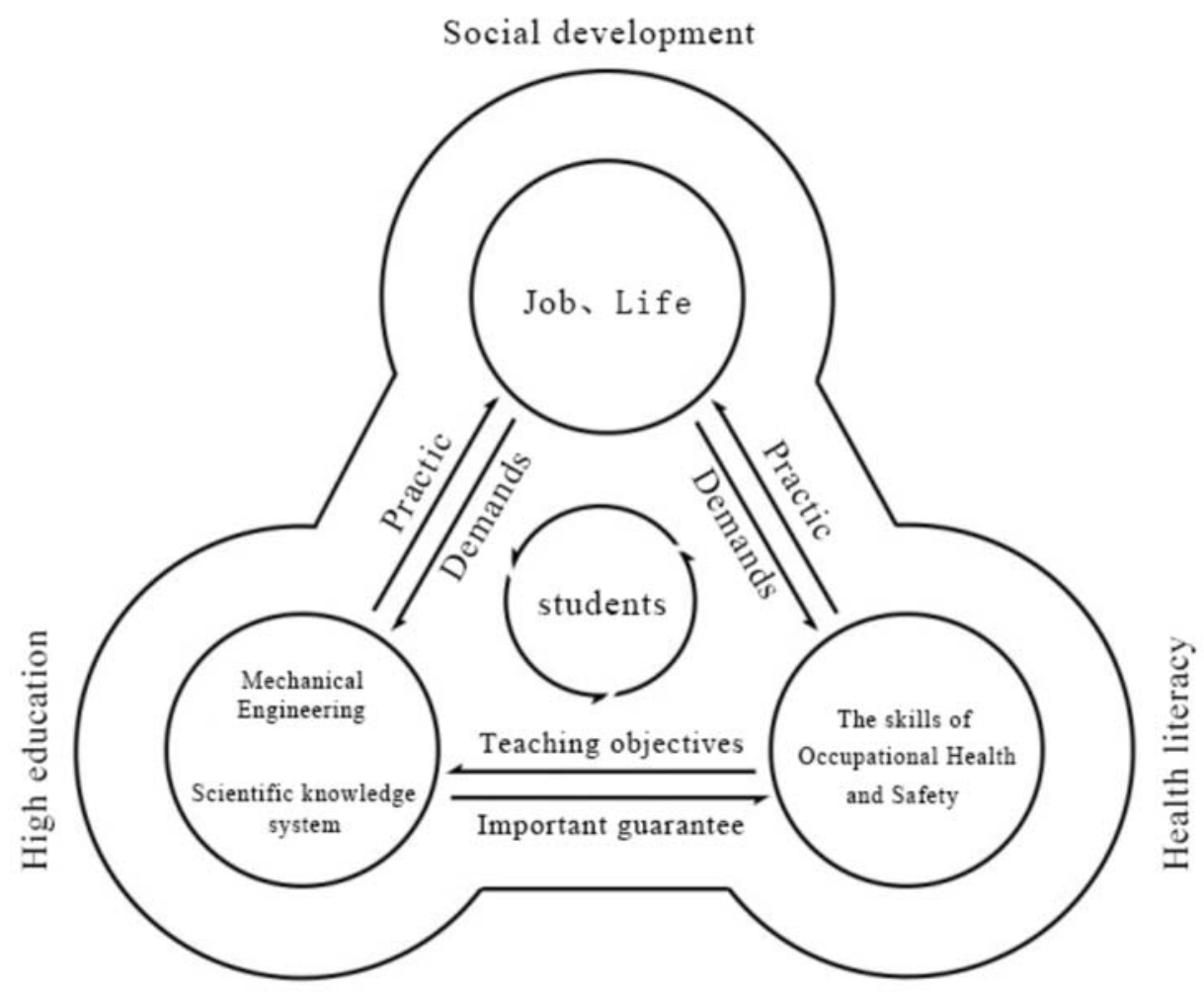

Fig.2.2 The relationship between the knowledge system of mechanical engineering and the skills of occupational health and safety 
One of the teaching objectives of training system of mechanical engineering is to master the occupational health and safety knowledge and skills. The courses of mechanical engineering are also important guarantee (Fig.2.2). Occupational health and safety knowledge and skills can be integrated into these module.

\section{The Construction of Occupational Safety Knowledge System in Engineering}

\subsection{Studying on the teaching system and teaching contents}

The educators should study on the relationship between the various subsystems in the teaching system, and form a harmonious teaching system. In the process, the basic courses should pay attention to instill the concept of occupational health care into students. The professional courses should pay attention to impart occupational health knowledge and skills. All kinds of courses of practice should focus on the realization of occupational health.

From integrating resources, the studengts ought to focus on the basic and expertise knowledge of occupational health and safety, to learn more about the origins, classifications and characteristics of the occupational hazards, and to master protective measures and control methods of the occupational hazards. In the classroom, the educators may set up the interactive platform composed by different professional of teachers and students, in the way of "joint team, collaborative management ", the platform aimed to help students work together in the range of different majors and grades, and it can deepen awareness of occupational health and safety. Then guiding students to concern and experience occupational health and safety, experience the professional environment and achieve innovative curriculum design. Carrying out the teaching mode of guiding by teachers and interacting between students and teachers, which is based on the core of comprehensive innovation. In the process, the teachers tried to achieve a series of teaching steps: teaching according to students' abilities; combinating theories with practices; combinating classroom with homework; spreading views on the surface of whole occupational care, and focusing on some importent fields.

Teaching contents are divided into several modules, mainly including: beginning to recognize the sources, classifications and characteristics of occupational hazards; studying some control methods to reduce occupational hazards; monitoring the parameters of working environment; researching how to control the index of occupational hazards. We will analyze these occupational hazards according to ergonomics, in order to solve the problems of health hazards more better and enhance the values of this study.

\subsection{Researching on the teaching methods and means}

In order to implement above teaching ideas, school teachers should research on multifaceted, multilevel, and multiform teaching methods and means to explore the complementary relationships of classroom teaching, online teaching, and practice teaching and so on. Researching the system structure of teaching resources oriented to "the idea of engineering occupational health", to provide the necessary and sufficient teaching resources for the people-centered teaching. In addition to classroom teaching, the teachers have studied on the following practice activities:

1) Researching safety warning signs by identification activities. Dividing the students into groups; collecting and studying the safety logos; scoring by the means of competition, and taking the total scores of each group as parts of the final points. Thus, mobilizing the enthusiasm of students, creating their safety awareness when students meet the logos.

2) Analyzing the typical examples of occupational health and safety. Taking the course Ergonomics as the core, setting up a series of engineering safety courses. Through typical cases, promoting students to analyze various elements of health hazard and safety risks, and studying how to prevent. Cultivating students' abilities of prevent, control and eliminate hidden dangers and to improve their abilities of holding occupational health and safety by interactive learning.

3) Training by visiting occupational environment, etc. Leading students to visit the works area, search for the questions about occupational health and safety and record. Through the curriculum design and researching solutions in Ergonomics, to ensure students can solve the safety problems in engineering practice. 


\subsection{Building the teaching evaluation system}

Reforming the single engineering technology-based evaluation system, and establishing a comprehensive evaluation system. In the teaching model, which is oriented to "engineering occupational health", we emphasize the initiative and creativity of students and reinforce the impact of engineering technology on human health. When it comes to teaching content and practice of comprehensive evaluation, the educators should expand the evaluation of the main elements and embody a wide range of evaluations including the self-evaluation, mutual assessment, and teacher evaluation, so that the education evaluation system more comprehensive and may play its important role.

\section{Conclusions}

This project has broken the traditional mode of teaching thinking, while introducing the concept of health into the occupation education, and implementing the whole teaching system and related courses, finally, building the idea of engineering education by taking health as the core. In this paper, authors tried to establish the systematic, scientific, harmonious engineering occupation health teaching system, to make students really both be equipped with technical engineering knowledge and have good cultural qualities. These really achieve people's desire to work well and healthily.

\section{Acknowledgement}

The successful completion of this paper depends on researching achievement of the teaching research project of Hefei University of Technology, which is based on the study of Engineering Occupational Health-oriented Engineering Students' Training System. Thanks to the funding and research conditions provided by Hefei University of Technology

\section{References}

[1]Gayle Woodside, Dianna Kocurek, Environmental, safety, and health engineering, Chemical Industry Press, Beijing. 1-316 (2006)

[2]Ding, Ergonomic, Beijing Institute of Technology Press (Fourth edition). 1-224 (2012)

[3]Zhang L, Occupational Hazards and Health Care, China Labour and Social Security Publishing House, Beijing. 1-146 (2010)

[4]Xu S Q, The Importance of Occupational Health and Safety Education to Vocational Education, Educational and Management Institute. 131-133 (2011)

[5]Turk Michelle Ann, Gambling with lives: A history of occupational health in southern Nevada.265-362(1905-2010)

[6]Antwi Andrea, Occupational health and safety among commercial sex workers in Ghana.2-29(2013)

[7]Shepherd, Mark A, Community, environmental, and occupational health risks associated with fossil fuel energy production.7-88(2015)

[8]Schwatka, Natalie V, Managing through measurement: Occupational health and safety in the construction industry.55-72(2014) 